\title{
Technology and Work-Life Conflict of Academics in a South African Higher Education Institution
}

\author{
Kajal Kotecha \\ Wilfred Ukpere \\ Madelyn Geldenhuys \\ Department of Industrial Psychology and People Management, Faculty of Management \\ University of Johannesburg, Johannesburg, South Africa \\ E-mail:wiukpere@uj.ac.za
}

\section{Doi:10.5901/mjss.2014.v5n2p629}

\begin{abstract}
The use of Information Communication Technologies (ICTS) to work after regular working hours has become prevalent in the academic profession. Although ICTs are known to enhance work flexibility, they also seem to encourage academics to use ICT devices after hours for work-related purposes. The objective of this study was to investigate the implications of technologyassisted supplemental work (TASW) on the work-life conflict (WLC) of academics. The moderating role of gender was also taken into consideration in investigating the relationship between TASW and WLC. The study adopted a quantitative research approach and made use of an online survey to collect data. The WLC scale and the TASW scale were used. The sample consisted of academics from a higher education in South Africa $(n=216)$. The results of the research revealed a significant relationship between TASW and WLC. TASW is a significant predictor of WLC. Furthermore, the results revealed that gender significantly moderated the relationship between TASW and WLC. This study contributes further knowledge to the emerging field of research relating to TASW in a South African context. This study also emphasises the implications of using ICTs and their potential to encourage academics to extend their working hours. This study therefore questions the benefits of this work flexibility that many academics are privileged to have from using ICTs.
\end{abstract}

Keywords: Information communication technologies, work-life balance, work-life conflict, technology-assisted supplemental work, academia, higher education institutions

\section{Introduction}

In recent years, academic work has become more challenging and demanding as higher education institutions in South Africa and across the world continue to transform (Santos \& Cabral-Cardoso, 2008). The literature pertaining to academia has consistently reported an increase in academics' workload (Gornall \& Salsibury, 2012; Tight, 2010). According to Tight (2010), universities, research councils and the government seem to demand more from academics without adequately rewarding them for their efforts. These demands experienced by academics may explain the long working hours that have become "the norm" in contemporary universities (Santos \& Cabral-Cardoso, 2008, p. 443). O'Laughlin and Bischoff (2005) report that on average, academics work for approximately 55 hours per week. More so, a large proportion of academics are increasingly working during evenings and weekends to engage in work-related activities such as marking, reading, writing reports and doing research (Gornall \& Salsibury, 2012; Kinman \& Jones, 2008; O'Laughlin \& Bischoff, 2005; Santos \& Cabral-Cardoso, 2008). Furthermore, academics tend to work more on their own research and publications after hours and, in addition make use of their vacation time to attend or present at research conferences (Santos \& Cabral-Cardoso, 2008).

Technological advancements in Information Communication Technologies (ICTs), have however, further enabled academics to engage in work-related activities "after hours" from anywhere and anytime without physically being at the office (Boswell \& Olson-Buchanan, 2007, p. 593). Thus, the pervasive nature of ICTs enables academics to stay connected to their workplace even though they may not be "formally on the job" (Boswell \& Olson-Buchanan, 2007, p. 593). For example, an academic may answer a work-related call during the evening or when on leave.

Although ICTs are known to increase academics' work freedom and flexibility, ICTs also encourage academics to engage in technology-assisted supplemental work (TASW), which has resulted, in academics working longer hours 
(Currie \& Eveline, 2010; Heijstra \& Rafnsdottir, 2010). This has raised important questions pertaining to the work-life balance (WLB) facilitated by ICTs and whether they do enhance or impede academics' WLB (Harmer, Pauleen \& Schroeder, 2008; Middleton, 2007). In particular, using ICTs to pursue work-related activities after hours blurs the traditional boundaries between work and family life, and, as a result, creates work-life conflict (WLC) (Boswell \& OlsonBuchanan, 2007; Chesley, 2005; Kakabadse, Porter \& Vance, 2009; Messersmith, 2007; Richardson \& Benbunan-Fich, 2011). Hence, the new work pattern of working after hours enabled by innovative ICTs has the dual purpose of both enhancing WLB balance and creating WLC due to the close integration of work and non-work domains.

\section{Problem Statement}

Modern ICTs have transformed academics' work practices. The work flexibility in the academic profession has traditionally been associated with enhanced WLB. However, the problem is that the almost $24 / 7$ connectivity facilitated by ICTs encourage academics to work longer hours by engaging in TASW. This may subsequently have a negative impact on academics' WLB that may result in academics experiencing WLC.

\subsection{Research Questions}

This study investigates the following research questions:

- To what extent do academics within a higher education institution in South Africa use ICTs after normal working hours to engage in TASW?

- What is the nature of the relationship between TASW and WLC?

- What type of WLC do academics within a higher education institution in South Africa significantly experience the most?

- To what extent do demographic factors influence the relationship between TASW and WLC?

\subsection{Primary Research Objective}

The primary research objective of this research is:

- To investigate the phenomenon of technology-assisted supplemental work among academic staff within a higher education institution in South Africa and the implications that TASW has on the WLC experienced by academics

\subsection{Secondary Research Objectives}

The secondary research objectives of this research are:

- To determine whether academics within a higher education institution in South Africa engage in TASW.

- To determine whether academic staff within a higher education institution in South Africa experience WLC as a result of engaging in TASW.

- To examine the relationship between TASW and WLC.

- To determine the type of WLC that is mainly experienced by academic staff within a higher education institution in South Africa

- To determine the role of demographic variables in influencing the relationship between TASW and WLC.

\section{Literature Review}

\subsection{Technology-assisted supplemental work}

Supplemental work is a phenomenon that has progressively gained attention in recent years and has previously been investigated by Venkatesh and Vitalari (1992) and Duxbury, Higgins and Thomas (1996). Supplemental work has been defined as "a form of distributed work where full-time employees work at home after regular working hours at night or on weekends" (Fenner \& Renn, 2004, p. 179). To give an example, an academic may spend time in the evening reading work-related documents in preparation for a meeting the following day. Consequently, the work performed by employees at home supplements (increases) the time spent at the office (Duxbury et al., 1996). 
However, the increased possibility of engaging in supplemental work has increased due to the constant connectivity enabled by ICTs (Fenner \& Renn, 2004; Venkatesh \& Vitalari, 1992; Hanson, 2007). Fenner and Renn (2004, p. 179) coined the term 'technology-assisted supplemental work' (TASW), which they define as the "performance of role-prescribed job tasks by full-time employees with the aid of advanced information and telecommunications technology at home or when away from home while on holiday". For instance, TASW is evident when employees answer their cell phones during family dinners (Boswell \& Olson-Buchanan, 2007). This form of distributed work is mainly performed by white-collar workers and does not constitute any compensation agreement (Fenner \& Renn, 2010). Furthermore, TASW is dependent on technological tools such as emails, smart phones, computers and wireless devices, which successfully enable work to be performed from non-traditional workplaces more efficiently (Fenner \& Renn, 2004).

\subsection{Work-life conflict}

One of the top priorities for many working individuals today is to maintain a balance between work and non-work domains (Sturges \& Guest, 2004). According to Duxbury, Higgins and Lee (1994), WLC is a result of not being able to achieve a balance between an individual's work domain and family domain. WLC has been defined by Greenhaus and Beutell $(1985$, p. 77$)$ as "a form of inter-role conflict in which the role pressures from the work and family domains are mutually incompatible in some respect". The incompatible role pressures that arise from both domains have an impact on individuals' performances in other roles (Carlson, Grzywacz \& Zivnuska, 2009; Greenhaus, Allen \& Spectator, 2006). For the purposes of the current study and taking into account the aim of investigating the impact of using ICTs to work after hours, the researchers specifically focus on how work creates conflict in an academic's personal life (which also includes their family life).

Greenhaus and Beutell (1985) identified three main forms of WLC, namely, behavioural-based conflict, time-based conflict, and strain-based conflict. In particular, the study focuses on three dimensions, namely, behavioural-based work interference with family, time-based work interference with family, and strain-based work interference with family. Behavioural-based conflict is when certain behaviours that are necessary in one role are incompatible with the behaviours that are expected in another role (Greenhaus \& Beutell, 1985). Time-based conflict occurs when the time spent in one role (for example, work) makes it difficult to participate in another role (for example, family and/or personal relationship) (Greenhaus \& Beutell, 1985; Messersmith, 2007). Strain-based conflict is when strain experienced in one role makes it difficult and challenging to participate in another role. For example, stress experienced at work is transferred or 'spills-over' onto another role, which consequently reduces an individual's effectiveness in that role (Greenhaus \& Beutell, 1985; Greenhaus et al., 2006; Messersmith, 2007). Examples of work sources that create strain include role conflict and role ambiguity.

\subsection{TASW and WLC among academics}

It is now an accepted fact that academics are increasingly working beyond the normal working hours (Currie, Harris \& Thiele, 2000; Houston, Luanna \& Paewai, 2006). Working normal hours is associated with a 9am to 5pm work schedule that runs from Monday to Friday (Kinman \& Jones, 2008). Westenholz (2006) further explains that 'normal working hours' involves working for 40 hours per week with the weekend free. Academics however are often working during the evenings and weekends so as to cope with the escalating work demands and work pressures (Houston et al., 2006; Kinman \& Jones, 2008; O'Laughlin \& Bischoff, 2005). Kinman and Jones (2008) found that 66 percent of academics in their study reported to have worked for more than 45 hours per week, while 24 percent worked for more than 55 hours. Higgins and Duxbury (2005) further explain that working long hours in today's competitive business environment is seen as necessary in order to succeed in one's career. This is also applicable to any academic who is constantly required to publish research. In fact, according to Jacobs and Winslow (2004), if research output is considered essential in order to be successful in academia, then working more than 60 hours per week becomes an inevitable requirement in the academic profession.

However, recent studies have started questioning the work flexibility facilitated by ICTs. Hewlett and Luce (2006) argue that the constant connectivity enabled by ICTs have changed individuals' behaviours and expectations. Middleton (2007) found that many individuals connect their emails to their BlackBerrys even when they are on holiday. Heijstra and Rafnsdottir (2010) found that academics often have difficulty in detaching themselves from work when they are on family holidays. For instance, many academics feel tempted to take their laptops and cell phones with them in order to stay connected to their work. However, there are indeed academics who wish to go on holiday to locations where they do not 
have access to ICTs so that they do not feel compelled to attend to work-related activities (Heijstra \& Rafnsdottir, 2010). The constant availability of ICTs has therefore been regarded by researchers as both a "blessing and a curse" (Currie \& Eveline, 2010; Harmer et al., 2008; Hewlett \& Luce, 2006). Furthermore, researchers argue that, although ICTs enhance flexibility, they do, however, increase academics' workload, extend their working day and even encourage academics to persistently engage in work-related activities due to the ubiquitous nature of ICTs (Currie \& Eveline, 2010; Heijstra \& Rafnsdottir, 2010). This consequently has a negative impact on the individual's family and life, resulting in WLC (Batt \& Valcour, 2003; Heijstra \& Rafnsdottir, 2010).

Based on the above discussion, the following hypothesis was generated:

H1: Academics within a higher education institution in South Africa use ICTs after normal working hours to engage in supplemental work practices.

\subsection{The consequences of TASW and the relationship with WLC}

Previous studies have been inconsistent with regard to the consequences of TASW. While some researchers propose that employees who engage in TASW at home perform better than colleagues (Venkatesh \& Vitalari, 1992), other researchers seem to argue differently. For example, Allen, Renn and Griffeth (2003, as cited in Fenner \& Renn, 2004, p. 180) explain that employees may not perform better from engaging in TASW as a result of interruptions that arise from family and friends. Furthermore, TASW has also been associated with increased stress and family dissatisfaction as well as WLC (Batt \& Valcour, 2003; Chesley, 2005; Kaufman-Scarborough, 2006). Parasuraman and Simmers (2001) explain that the use of ICTs to work from home increases the integration between work and family boundaries, consequently encouraging overworking, individualism and interruption.

Furthermore, working long hours has also been positively associated with WLC (Batt \& Valcour, 2003; Skinner \& Pocock, 2008). Additionally, Kinman and Jones (2008) found that academics who worked during the evenings and on weekends experienced more WLC than academics who did not work after hours. It is therefore not surprising that studies in this field of research have suggested and found a significant relationship between TASW and WLC (Boswell \& OlsonBuchanan, 2007; Fenner \& Renn, 2010; Fenner \& Renn, 2004; Messersmith, 2007). These studies reveal a positive relationship between TASW and WLC. Hence, academics who engage in TASW are more likely to experience WLC. The reason for this, as explained by Boswell and Olson-Buchanan (2007), is that, as individuals devote more time to work at home, it becomes extremely difficult to fulfil the role requirements and demands in the non-work domain. Accordingly, academics may experience time-based WLC. In addition, psychologically, academics have to be able to disengage themselves from their family and other non-work activities so as to engage in work-related activities (Fenner \& Renn, 2004; Messersmith, 2007). Similarly, Kinman and Jones (2008) found in their study that academics often reported being preoccupied with work during non-working hours and having trouble relaxing and sleeping. This may further generate additional strain-based conflict (Messersmith, 2007). Furthermore, continuous concentration on work at home may lead academics to ignore the requirements and expectations of family members while in the non-work domain (Fenner \& Renn, 2010). Thus, working after hours, with the aid of ICTs, may further create behavioural-based WLC in addition to time- and strain-based WLC as explained previously.

Based on the above discussion, the following hypothesis was generated:

H2: There is a significant relationship between TASW and WLC among academic staff within a higher education institution in South Africa.

\subsection{Gender, TASW and WLC}

According to Boswell and Olson-Buchanan (2007), individuals will experience lower levels of WLC if engaging in TASW is considered the norm and an accepted work practice in a certain profession. It can therefore be expected that, since working long hours has become the norm in academia, the WLC experienced by academics may not be very high. However, various studies have found that academics who engage in supplemental work practices at home still do experience higher levels of WLC (Currie \& Eveline, 2010; O'Laughlin \& Bischoff, 2005; Heijstra \& Rafnsdóttir, 2010; Rafnsdóttir \& Heijstra, 2011). In addition, Fenner and Renn (2004) suggest that time and boundary management skills mediate the relationship between TASW and WLC. 
Research also suggests that demographic factors such as gender, parental status, marital status and job position play an important role in influencing this relationship (Boswell \& Olson-Buchanan, 2007; Parasuraman \& Simmers, 2001; Venkatesh \& Vitalari, 1992). For the purposes of this paper, the researchers specifically focus on the role of gender in moderating the relationship between TASW and WLC. Ojala (2011) found that men engaged in supplemental work slightly longer than women. However, this result was not statistically significant, indicating that there are no gender differences in engaging in supplemental work practices (Ojala, 2011). Additionally, previous studies report that women tend to experience higher levels of WLC than men due to the 'double burden' responsibilities of both paid and unpaid work (Russell, Connell \& McGinnity, 2009, p. 89). Similarly, Duxbury et al. (1994) reported that women in their study experienced slightly more WLC than men. However, in an Iranian study, Karimi (2008) found no gender differences attributed to the extent to which men and women experience WLC.

Based on the above discussion, the following hypothesis has been generated:

H3: Gender moderates the relationship between TASW and WLC

\section{Research Methodology and Approach}

This study adopted a quantitative research approach in order to answer the research questions and to address each of the research objectives. In particular, a cross-sectional research design was used.

\subsection{Sampling Procedure}

This study used two-non-probability sampling methods, namely purposive and convenience sampling to select academics from a higher education institution in South Africa. It should be emphasised that these sampling methods are not representative of the population and were selected based on the researchers' judgement about the academic profession and the increasing work demands. In total, 1033 emails were sent out to academic staff to participate in the online survey. After two weeks, 263 surveys were obtained. However, after the screening process and excluding respondents who were part-time, a total of $\mathbf{2 1 6}$ usable surveys were obtained. This therefore resulted in a response rate of $21 \%$.

\subsection{Participants}

The demographic profile of the respondents in the current study is as follows. The sample consists of 130 female respondents $(\mathbf{6 0 . 2 \% )}$ and 85 male respondents $(39.4 \%)$. The respondents' ages vary from between 25 to 40 years $(45.8 \%)$ and from 41 to 66 years $(49.8 \%)$. Regarding the race of the respondents, the majority of sample is White $(62.7 \%)$, followed by African Black (22.1\%). Furthermore, the sample is primarily dominated by respondents who are married $(67.8 \%)$ and thereafter followed by academics who are single (19.7\%). In terms of children, $62.0 \%$ of respondents in the sample have children. Furthermore, of the $62.0 \%$ of respondents who have children, $24.5 \%$ have two children followed by $19.4 \%$ who have one child. In addition, $70.1 \%$ of respondents do not have a dependent who is not their own child, while $29.9 \%$ have a dependent other than their own child.

The majority of respondents' home language is English (44.8\%), followed by Afrikaans (38.4\%), Nguni (7.9\%), Sotho (7.4\%) and lastly, Venda/Tsonga (1.5\%). In terms of educational qualifications, the respondents in the sample mainly have a master's qualification (48.4\%) followed by a doctoral degree (44.6\%), honours degree (4.6\%), bachelor's degree (1.4\%), certificate/diploma (.5\%) and, lastly, matric (.5\%). Additionally, the sample primarily comprises respondents with a lecturer designation (45.2\%) followed by a senior lecturer (28.1\%), associate professor (10.5\%), professor (9.0\%), head of department (5.7\%) and, lastly, a researcher (1.0\%). The sample was screened to include only full-time academic staff. This therefore resulted in a total sample of 216 full-time academic staff (100\%). Furthermore, the majority of respondents $(36.4 \%$ ) indicated that they work after hours for between 3 and 4 hours per day while $30.3 \%$ work after hours for between 1 and 2 hours per day. It should be noted that $14.0 \%$ of respondents spend 7 or more hours working at home, while $13.5 \%$ spend between 5 and 6 hours per day working after regular working hours at home. Lastly, $5.8 \%$ of respondents spend less than an hour on work-related activities after hours at home using ICTs. Furthermore, $\mathbf{8 7 . 9 \%}$ of respondents indicated that their institution provides them with a laptop or a similar ICT device for work-related purposes. A small proportion of $12.0 \%$ indicated that their institution does not provide them with ICTs for their work. 
Lastly, in terms of the type of ICTs used to engage in TASW, the majority of respondents $(\mathbf{9 1 . 7 \% )}$ mainly use their laptops followed by their smartphones (48.8\%), Tablet (41.2\%) and their desktop computer (20.4\%).

\subsection{Measuring Instruments}

The online survey used in the current study consists of three sections that included the following:

\section{Demographic Questions}

This section of the survey provides general demographic related information about respondents participating in the study. These include the age, gender, race, educational qualification, marital status and home language. Additional questions related to academic staffs' designation, their employment type as well as the number of hours spent per day using ICTs to work after hours. Furthermore, academics were asked to indicate the type of ICT devices, which they use to engage in TASW and whether their institution provides them with any ICTs for work-related purposes.

\subsection{Work-life conflict}

A shortened version of 9 items in Carlson Kacmar and Williams (2000) WLC scale was used to assess the WLC experienced by academic staff in all three forms of WLC: 1) behavioural-based work interference with family; 2) timebased work interference with family; and 3) strain-based work interference with family. Thus, the 9 items that assess each of these sub-constructs were the main focus of the current study. The items were rated on a five-point Likert scale, ranging from (1) 'strongly disagree' to (5) 'strongly agree'. The following are some examples of behavioural-, time- and strain-based work interference with family statements, respectively: "The problem-solving behaviours I use in my job are not conducive to resolving problems at home"; "My work keeps me from my family activities more than I would like"; "Due to all the pressures at work, I often come home too stressed to do the things I enjoy" (Carlson et al., 2000, p. 260).

Carlson et al. (2000) assessed the internal consistency of all six items with coefficient alpha. The results revealed that all six items are reliable with high Cronbach's alpha coefficient values of above the accepted .70 (Carlson et al., 2000).

\subsection{Technology-assisted supplemental work}

A recently developed TASW scale, by Fenner and Renn (2010), was used to determine whether academic staff in a higher education institution in South Africa use ICTs to work after regular working hours. The scale consists of six items which were rated on a five-point Likert scale, ranging from (1) 'never' to (5) 'always' (Fenner \& Renn, 2010). An example of an item in this scale includes: "I perform job-related tasks at home, at night, or on weekends, using my cell phone, pager, BlackBerry or computer" (Fenner \& Renn, 2010, p. 70). The five-item scale was reported as reliable with a Cronbach's coefficient alpha value of .88 (Fenner \& Renn, 2010).

\subsection{Procedure}

This research was conducted only after permission was granted from the Ethics Committee and from the higher education institution. In addition, an explanatory statement was included on the first page of the online survey that explained the purpose of the study and further emphasised that participation in the online survey was voluntary and to be completed anonymously. Additionally, it was explained that all responses obtained from the online survey would be kept confidential and would not be disclosed to any third party who was not involved in the current study.

A pilot study was first conducted before formally distributing it to academic staff at the higher education institution. This was done to assess the reliability and validity of the online survey. The online survey was then launched after addressing the recommended changes from the pilot study. Following the pilot study, an email was sent out to all academic staff inviting them to participate in the research study. The email content briefly explained the rationale of the study and emphasised the anonymity and confidentiality of their responses. The email included the URL link to the webbased survey, which directed respondents to the online survey. The data was collected over a period of two weeks. Additionally, a reminder email was also sent a week after the initial email. Once academic staff completed the survey, their responses were anonymously and automatically recorded on the system. 


\subsection{Statistical Analysis}

The data from the online survey responses was retrieved electronically by using the Statistical Package for Social Sciences (SPSS). The data was first screened and cleaned before conducting any analyses on the data. In particular, the two negatively phrased statements in the TASW were reversed before proceeding to the analysis. Cronbach's alpha coefficients were used to assess the reliability of the constructs that were used in this study. Descriptive Statistics, such as the means, standard deviations, skewness and kurtosis were used to describe and summarise the data obtained from the online survey responses. Inferential statistics, such as correlations and multiple regressions were also used to analyse the data. Pearson's correlation coefficient was used to assess the relationship between TASW and WLC. Furthermore, a linear regression was used to predict WLC from TASW.

In addition, a separate, three-step, hierarchical multiple regression analysis was computed for WLC as a predictor; TASW as the main effect and gender as the moderator. It should be noted that for the multiple hierarchical regression analysis, the variables were centred. In the first step, the predictor variable (TASW) was entered into the regression model, the moderator (gender) in the second step, followed by their interaction (for example, TASW $x$ gender) in the third step.

\section{Results}

\subsection{Descriptive Statistics for TASW and WLC}

Table 1 presents the means, standard deviations, skewness and kurtosis and Cronbach's alpha coefficient values of the following variables: total TASW score, total time-based WLC, total strain-based WLC, total behavioural-based WLC and total WLC score.

Table 1: Descriptive statistics and Cronbach's alpha coefficients (a) of the constructs

\begin{tabular}{lccccc}
\hline \multicolumn{1}{c}{ Construct } & Mean & Std. Deviation & Skewness & Kurtosis & $\boldsymbol{\alpha}$ \\
\hline Total TASW & 25.58 & 3.65 & -.870 & .446 & .84 \\
Total time-based WLC & 9.52 & 3.12 & -.213 & -.837 & .89 \\
Total strain-based WLC & 8.97 & 3.22 & -.033 & -.999 & .89 \\
Total behavioural-based WLC & 7.67 & 2.51 & .160 & -.296 & .82 \\
Total WLC & 26.07 & 7.14 & -.135 & -.710 & .88 \\
\hline
\end{tabular}

The total TASW score has a mean value of 25.58 and standard deviation of 3.65. This indicates that academics within this higher education institution seem to use ICTs after normal working hours to engage in supplemental work practices. Hence, hypothesis 1 is supported in the current study. Furthermore, it can be seen from Table 1 that respondents seem to experience slightly more time-based WLC $(M=9.52, S D=3.12)$ followed by strain-based $W L C(M=8.97, S D=3.22)$, and, thereafter, behavioural-based WLC $(M=7.67, S D=2.51)$. The overall WLC score has a mean score of 26.07 and standard deviation of 7.14. Thus, from the mean values, academic staff members from this higher education institution seem to experience all three forms of WLC.

The internal consistency (reliability) of each scale was assessed by calculating Cronbach's alpha coefficient. This is referred to as the extent to which all items in the scale measure the same construct (Pallant, 2009). Furthermore, Nunnally (1978, as cited in Bernardi, 1994, p. 767) states that a Cronbach's alpha coefficient value of 7 is regarded as acceptable while values above .8 are desirable. The table presents the Cronbach's alpha coefficient values for all TASW scale and sub-scales of the WLC scale. It is evident that each of the scales has a Cronbach's Alpha Coefficient value of above .8. Thus, all the scales are highly reliable with the current study's sample as suggested by Nunnally (1978, as cited in Bernardi, 1994, p. 767). These findings are also consistent with those of Fenner and Renn's (2010) and Carlson et al. (2000) for TASW and WLC, respectively.

\subsection{The relationship between TASW and WLC}

Table 2: The correlation between TASW and WLC

\begin{tabular}{rrrrrr}
\hline Scale & 1 & 2 & 3 & 4 & 5 \\
\hline 1. Total TASW & - & & & & \\
\hline & 6 & $\bullet$ & & & \\
& 635 & & &
\end{tabular}




\begin{tabular}{llllll}
\cline { 2 - 5 } & 2. Total time-based WLC & $.398^{\star \star}$ & - & & \\
3. Total strain-based WLC & $.250^{\star \star}$ & $.661^{\star \star}$ & - & \\
4. Total behavioural-based WLC & -.015 & $.308^{\star \star}$ & $.440^{\star \star}$ & - \\
5. Total WLC & $.284^{\star \star}$ & $.845^{\star \star}$ & $.887^{\star \star}$ & $.671^{\star \star}$ & - \\
\hline${ }^{* *} p<.001$ (2-tailed) & & & & &
\end{tabular}

Table 2 shows the Pearson correlation between TASW and WLC. The Pearson Correlation revealed a significant positive relationship between TASW and WLC $(r=.28, n=193, p<.01$, two tailed). However, as suggested by Cohen, the strength of this relationship is small (1988, as cited in Pallant, 2009). There is a small but significant relationship between TASW and WLC. On the basis of the above results, hypothesis 2 is accepted as the p-value is less than .01. Accordingly, this indicates that the relationship between TASW and WLC is statistically significant and not as a result of chance.

Furthermore, the table also presents the relationship between TASW with each of the WLC sub-scales. There is a positive significant correlation between TASW and time-based WLC $(r=.39, \mathrm{n}=195, p<.01)$ as well as with strainbased WLC $(r=.25, \mathrm{n}=199, p<.01)$. Hence, as academics engage in TASW, they also experience time-based and strain-based WLC. Interestingly, however, it should be noted that there is a negative relationship between TASW and behavioural-based WLC which is not significant $(r=-.15, n=199, p>.01)$. With the exception of behavioural-based WLC, academics within this higher education institution in South Africa significantly experience both time-based and strain-based WLC as a result of engaging in TASW. These results further enhance the overall findings of the relationship between TASW and WLC.

Table 3: Multiple regression of WLC as the dependent variable and TASW and gender as the independent variables

\begin{tabular}{|c|c|c|c|c|c|c|c|c|c|c|}
\hline \multirow[t]{2}{*}{ Model } & & \multicolumn{3}{|c|}{ Unstandardised Coefficient Standardised Coefficient } & \multirow[t]{2}{*}{$t$} & \multirow[t]{2}{*}{$P$} & \multirow[t]{2}{*}{$F$} & \multirow{2}{*}{\multicolumn{3}{|c|}{$\begin{array}{lll}R & R^{2} & \Delta R^{2}\end{array}$}} \\
\hline & & $B$ & SE & Beta & & & & & & \\
\hline \multirow[t]{2}{*}{1} & Constant & 12.22 & 3.43 & & 3.56 & .00 & 16.77 & .28 & .08 & .07 \\
\hline & TASW & .54 & .13 & .28 & 4.09 & $.00 *$ & & & & \\
\hline \multirow[t]{3}{*}{2} & Constant & 8.68 & 3.83 & & 2.26 & .02 & 10.46 & .31 & .10 & .09 \\
\hline & TASW & .554 & .135 & .28 & 4.10 & $.00 *$ & & & & \\
\hline & Gender & 2.00 & 1.00 & .13 & 1.99 & $.04^{*}$ & & & & \\
\hline \multirow[t]{4}{*}{3} & Constant & -20.47 & 11.91 & & -1.71 & .08 & 9.40 & .361 & .13 & .11 \\
\hline & TASW & 1.67 & .45 & .85 & 3.68 & $.00^{*}$ & & & & \\
\hline & Gender & -86.95 & 34.48 & -5.96 & -2.52 & .01 & & & & \\
\hline & TASW X Gender & -4.20 & 1.62 & -6.13 & -2.58 & $.01^{*}$ & & & & \\
\hline
\end{tabular}

Table 3 reveals that in step1, TASW is a significant predictor of $\operatorname{WLC}\left[F_{(1,191)}=16.77 ; \beta=.28 ; p<.05\right]$. Accordingly, TASW explains $8 \%$ of the total variance in WLC. The inclusion of gender in the multiple regression $[\Delta F(1,191)=3.97 ; \beta=$ $.13 ; p<.05]$ accounts for $10 \%$ of the variance in WLC. It can be seen that, in the third step, an additional $2 \%$ of variance in WLC was increased. Therefore, the two-way interaction variable $\left[\Delta F_{(1,191)}=6.66 ; \beta=-6.13 ; p<.05\right]$ shows that gender significantly moderates the relationship between TASW and WLC. This therefore results in accepting hypothesis 3.

Figure 1: Graph illustrating the moderating effect of gender on TASW (main effect variable) and WLC (dependent variable)

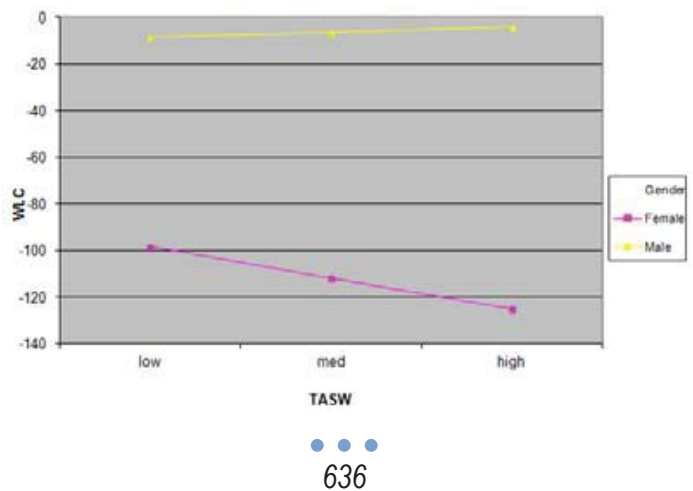


Figure 1 shows that female academics experience higher levels of WLC compared to men. Further, women tend to experience higher levels of WLC when they engage in TASW, while men seem to experience less WLC.

\section{Discussion of Result}

The primary objective of this study was to investigate the phenomenon of TASW among academic staff in a higher education institution in South Africa and the implications that TASW has on the WLC experienced by academic staff

\subsection{Academics engaging in TASW}

The current study affirms hypothesis 1 that academics do indeed use ICTs after normal working hours to engage in supplemental work practices. This could be attributed to the nature of the academic profession. As aforementioned in the literature, academia is referred to as a demanding profession whereby supplemental work practices and working long hours are considered to be the norms (Currie \& Eveline, 2010; Currie et al., 2000; Houston et al., 2006; O'Laughlin \& Bischoff, 2005; Santos \& Cabral-Cardoso, 2008). This also seems to be evident in the South African academic context as the majority of respondents in the study indicated that they used their laptops to work after hours at home for between 3 and 4 hours per day. It is possible that academics within this higher education institution engage in TASW as a result of increased workloads, for example, increased teaching, research, administration and community service responsibilities (Houston et al., 2006; Kinman \& Jones, 2008; Tight, 2010; Ylijoki, 2010). Furthermore, the competitive academic environment that requires academic staff to publish research may also encourage academics to engage in TASW (Jacobs \& Winslow, 2004; Rafnsdóttir \& Heijstra, 2011).

\subsection{Relationship between TASW and WLC}

Hypothesis 2 was accepted as the results revealed a significant and positive relationship between TASW and WLC $(r=$ $.28, p<.01)$. This accordingly indicates that, as academics engage in TASW, they also experience higher levels of WLC. This result is consistent with previous studies which have also reported a positive relationship between TASW and WLC (Boswell \& Olson-Buchanan, 2007; Fenner \& Renn, 2010; Kinman \& Jones, 2008; Messersmith, 2007).

The significant and positive relationship between TASW and WLC can be attributed to the explanations provided by various researchers (Boswell \& Olson-Buchanan, 2007; Fenner \& Renn, 2004; Parasuraman \& Simmers, 2001). Firstly, the use of ICTs to engage in work-related activities after hours at home is known to blur the traditional boundaries between work and non-work domains (Boswell \& Olson-Buchanan, 2007; Currie \& Eveline, 2010; Higgins \& Duxbury, 2005). Boswell and Olson-Buchanan (2007) explain that the use of ICTs to work after hours makes it challenging for individuals to fulfil their work and non-work role demands.

However, it should be noted that the strength of the relationship between TASW and WLC is small according to the guidelines stipulated by Cohen (1988, as cited in Pallant, 2009, p. 134). A possible explanation of this could be attributed to the fact that although academics are known to have high workload demands, they are also more likely to have control over managing their time between both domains (Fenner \& Renn, 2010; Lewis, 2010). This consequently reduces WLC, as explained by Batt and Valcour (2003). It could thus be suggested that the strength of this relationship is small as academics in this sample may have good time and boundary management skills which reduces the WLC experienced from engaging in TASW (Fenner \& Renn, 2004). A further possible explanation of the relationship between TASW and WLC being minimal could be attributed to the fact that working long hours in the academic profession is the norm, and therefore an accepted practice. This is supported by Boswell and Olson-Buchanan (2007) who assert that individuals experience less WLC if working long hours and engaging in TASW are accepted practices.

It should further be noted that the linear regression revealed that TASW is a significant predictor of WLC. However, the results reveal that TASW only shares $8 \%$ of the variability in the WLC scores. This further means that $92 \%$ of the variability in the WLC scores is accounted for by other factors. Indeed, it is possible that TASW only explains a small percentage of variance in the WLC scores due to the phenomenon being relatively new and fewer studies having been conducted in this stream of research.

\section{The Relationship between TASW and the Three Forms of WLC}

Further analysis revealed that time-based and strain-based WLC are significantly and positively related to TASW. A 
possible reason for academics experiencing time-based WLC could be attributed to the fact that when academics engage in TASW at work, they spend more time working rather than spending that time with their family. This therefore creates time-based WLC as Boswell and Olson-Buchanan (2007) explain that it becomes challenging to fulfil the role requirements and demands of both domains. Consistent with Kinman and Jones' (2008) results, academics in the current study also experience strain-based WLC from engaging in supplemental work practices. A possible explanation for this could be that academics are psychologically unable to disengage themselves from their family when engaging in TASW at home (Messersmith, 2007). Interestingly, there was no significant relationship between TASW and behavioural-based WLC. This was unexpected as previous studies have suggested a positive relationship between TASW and behaviouralbased WLC (Fenner \& Renn, 2010). A possible explanation for the result not being positively significant could be attributed to the fact that the overall strength of the relationship between TASW and WLC is weak. It is further possible that academics do not engage in TASW as often, reducing the behavioural-based WLC that they would experience. Alternatively, as suggested previously, it is also possible that academics in this institution have good time and boundary management skills, reducing WLC, including behavioural-based WLC experienced as a result of engaging in TASW (Fenner \& Renn, 2010; Lewis, 2010).

\subsection{The effect of gender on the relationship between TASW and WLC}

It was tested whether engaging in TASW increases or reduces the WLC experienced by men and women academics. The relationship illustrated in Figure 1 shows that women academics experience more WLC than men academics, regardless of the extent to which they engage in TASW. Thus, this indicates that gender has a moderating effect on the extent to which academics experience WLC as a result of engaging in TASW.

A possible explanation for these results could be attributed to the traditional gendered role expectations regarding work and family responsibilities. Women have traditionally been associated with family and child-care responsibilities while men have been associated with being the sole breadwinners whose purpose is to provide for their families (Karimi, 2008; Parasuraman \& Simmers, 2001; Valcour, 2007; Venkatesh \& Vitalari, 1992). There is evidence in the literature suggesting that women experience higher levels of WLC due to the pressure of fulfilling the demands of both their work and family responsibilities (Russell et al., 2009). It is therefore possible that women academics within this institution experience more WLC from increasingly engaging in TASW due to the traditional gendered role expectations. The incompatible role demands that result from engaging in TASW at home create more WLC for female academics. On the contrary, traditional gender role expectations require men to engage in work (Boswell \& Olson-Buchanan, 2007). This therefore implies that men may not necessarily experience high levels of WLC typically experienced by women when they work after hours at home using ICTs.

\section{Limitations of Current Study}

The current study had some limitations that need to be taken into consideration while interpreting the findings of the current study. A limitation of this study is that no causal relationships can be established, as the current study adopted a cross-sectional research design. Furthermore, the results of this study cannot be generalised to other institutions or populations as the study was conducted using academic staff from a particular higher education institution in South Africa. In addition, the purposive and convenience sampling methods used in the current study also limit the ability to generalise the findings to a larger population. Additionally, individual differences, such as being ambitious or committed, were not included as part of the research study. Moreover, not all variables were included as possible moderators in influencing the relationship between TASW and WLC.

\section{Recommendations for Future Studies}

It is recommended that future studies adopt a longitudinal research design to investigate the phenomenon of TASW and its relationship with WLC. In addition, future studies should replicate the current study in other higher education institutions in South Africa. Similarly, studies could also extend their research using other professions. This will further determine whether similar results are found in other institutions and with other professions. It is also suggested that future studies adopt a random sampling method in order to be able to generalise the findings to a larger population. For the same reason, a larger sample size should also be used for future studies. It is also suggested that studies further explore the relationship between TASW and WLC by taking into account other factors such as stress and health and 
wellbeing. Furthermore, future studies should also investigate the role of behavioural-based WLC from engaging in TASW as this finding was contrary to what was expected.

\section{Recommendations to the Higher Education Institution}

In light of the results obtained in the current study, various recommendations, derived from the findings and supported by literatures, are made to the institution in order to reduce the WLC experienced by academics from engaging in TASW as discussed below.

\subsection{The development of clear policies pertaining to the use of ICTs after hours}

It is suggested that the institution develop clear policies and expectations about using ICTs for work-related purposes after hours. Specifically, it is recommended that the institution develops policies that limit the use of ICTs after normal working hours. These policies should also be applied during the evenings, on weekends and holidays and also when on leave.

\subsection{Change in communication behaviours}

Top management and superiors should play a further role in restricting staff from engaging in TASW by modelling the desired behaviour themselves. For example, top management should not send out emails during holidays as this creates a perception that staff should also engage in work practices after hours.

\subsection{Create awareness of the phenomenon of TASW and provide support in managing boundaries}

The institution should provide an information session about the phenomenon of TASW to academic staff. This will create greater awareness among staff members and will encourage them to manage their work and family boundaries more effectively. In addition, training could be provided on how staff members can restrict the practice of engaging in TASW.

\section{Contribution of Study}

This research was conducted in a South African context which is of significance as most previous studies pertaining to supplemental work and TASW have been conducted in USA, Canada and Finland (Boswell \& Olson-Buchanan, 2007; Duxbury et al., 1996; Fenner \& Renn, 2004; Fenner \& Renn, 2010; Ojala, 2010; Richardson \& Benbunan-Fich, 2011). The results of this study have therefore contributed to the existing field of literature relating specifically to the academic context and TASW. This is valuable as TASW is an emerging field of research that has not been studied extensively, specifically in South Africa.

The current study used Fenner and Renn's (2010) TASW scale in a South Africa context using academics in a higher education institution. However, as previously explained, Fenner and Renn (2010) suggested that their TASW scale be assessed using a different population. This study further questions the work flexibility enabled by ICTs and the role that they play in encouraging academics to engage in TASW. Hence, ICTs enhance work flexibility and WLB, but also however encourage academics to use ICTs after hours for work-related purposes, which consequently results in WLC. It is thus anticipated that the results obtained from this study will add value to the existing field of literature relating to the academic profession, TASW and WLC.

\section{Conclusion}

In conclusion, this research revealed that academics do engage in TASW and as a result also experience WLC. In particular, academics experience time-based and strain-based WLC. Furthermore, gender significantly moderates the relationship between TASW and WLC. The traditional advantage of using ICTs to enhance work flexibility also has a drawback of enabling academics to continue working even after regular working hours. This consequently blurs the boundaries between work and non-work domains and, creates WLC. Based on these findings, it becomes extremely imperative for academics and for the higher education institution to understand the implications of using ICTs for workrelated purposes after working hours. It is therefore advised that academics and the higher education institution consider 
the proposed recommendations in order to reduce the negative impact of engaging in supplemental work using ICTs.

\section{References}

Batt, R., \& Valcour, P. M. (2003). Human Resource Practices as Predictors of Work-Family Outcomes and Employee Turnover. Industrial Relations, 42(2), 189-220.

Bernardi, R. A. (1994). Validating Research Results when Cronbach's Alpha is Below .70: A Methodological Procedure. Educational and Psychological Measurement, 54(3), 766-775. doi:10.1177/0013164494054003023.

Boswell, W. R., \& Olson-Buchanan, J. B. (2007). The Use of Communication Technologies After Hours: The Role of Work Attitudes and Work-Life Conflict. Journal of Management, 33(4), 592-610. doi:10.1177/0149206307302552.

Carlson, D. S., Grzywacz, J. G., \& Zivnuska, S. (2009). Is work-family balance more than conflict and enrichment? Human Relations, 62(10), 1459-1486. doi:10.1177/0018726709336500.

Carlson, D. S., Kacmar, K. M., \& Williams, L. J. (2000). Construction and Initial Validation of a Multidimensional Measure of Work Family Conflict. Journal of Vocational Behavior, 56, 249-276. doi:10.1006/jvbe.1999.1713

Chesley, N. (2005). Blurring Boundaries? Linking Technology Use, Spillover, Individual Distress, and Family Satisfaction. Journal of Marriage and Family, 67, 1237-1248.

Currie, J., \& Eveline, J. (2010). E-technology and worklife balance for academics with young children. Higher Education, 62(4), 533550. doi:10.1007/s10734-010-9404-9.

Currie, J., Harris, P., \& Thiele, B. (2000). Sacrifices in Greedy Universities: Are they gendered? Gender and Education, 12(3), 269-291.

Duxbury, L. E., Higgins, C., \& Thomas, D. (1996). Work and Family Environments and the Adoption of Computer-Supported Supplemental Work-at-Home. Journal of Vocational Behavior, 23(49), 1-23.

Duxbury, L., Higgins, C., \& Lee, C. (1994). Work-Family Conflict: A Comparison by Gender, Family Type, and Perceived Control. Journal of Family Issues, 15(3), 449-466. doi:10.1177/019251394015003006.

Fenner, G. H., \& Renn, R. W. (2010). Technology-assisted supplemental work and work-to-family conflict: The role of instrumentality beliefs, organizational expectations and time management. Human Relations, 63(1), 63-82. doi:10.1177/0018726709351064.

Fenner, G. H., \& Renn, R. W. (2004). Technology-assisted supplemental work: Construct definition and a research framework. Human Resource Management, 43(2-3), 179-200. doi:10.1002/hrm.20014.

Greenhaus, J. H., Allen, T. D., \& Spector, P. E. (2006). Health consequences of work-family conflict: The dark side of work-family interface. Research in Occupational Stress and Well Being, 5, 61-98. doi:10.1016/S1479-3555(05)05002-X.

Greenhaus, J. H., \& Beutell, N. J. (1985). Sources of Conflict between Work and Family Roles. The Academy of Management Review, 10(1), 76-88.

Gornall, L., \& Salisbury, J. (2012). Compulsive Working, 'Hyperprofessionality' and the Unseen Pleasures of Academic Work. Higher Education Quarterly, 66(2), 135-154. doi:10.1111/j.1468-2273.2012.00512.x.

Hanson, J. (2007). 24/7 How well Cell Phones and the Internet Change the Way We Live, Work and Play. USA: Praeger Publishers.

Harmer, B., Pauleen, D. J., \& Schroeder, A. (2008). Cause or Cure : Technologies and Work-Life Balance. Informational Conference on Information Systems (ICIS) (pp. 1-15). Paris.

Heijstra, T. M., \& Rafnsdottir, G. L. (2010). The internet and academics' workload and work-family balance. Internet and Higher Education, 13(3), 158-163. doi:10.1016/j.jheduc.2010.03.004.

Hewlett, A., \& Luce, C. B. (2006). Extreme jobs: The dangerous allure of the 70-hour workweek. Harvard Business Review, (December), 49-59.

Higgins, C., \& Duxbury, L. (2005). Saying 'no' in a culture of hours, money and non-support. Ivey Business Journal, (519), 1-6.

Houston, D., Meyer, L. H., \& Paewai, S. (2006). Academic staff workloads and job satisfaction : Expectations and values in academe. Journal of Higher Education Policy and Management, 28(1), 17-30. doi:10.1080/13600800500283734.

Jacobs, J. A., \& Winslow, S. E. (2004). Overworked Faculty: Job Stresses and Family Demands. The ANNALS of the American Academy of Political and Social Science, 596, 104-129. doi:10.1177/0002716204268185.

Kakabadse, N. K., Porter, G., \& Vance, D. (2009). The unbalanced high-tech life: are employers liable ? Strategic Change, 18, 1-13. doi:10.1002/jsc.837.

Karimi, L. (2008). Do Female and Male Employees in Iran Experience Similar Work-Family Interference, Job, and Life Satisfaction? Journal of Family Issues, 30(1), 124-142. doi:10.1177/0192513X08324973.

Kaufman-Scarborough, C. (2006). Examining workspaces in the home. Time Society, 15(1), 57-80. doi:10.1177/0961463X06061782.

Kinman, G., \& Jones, F. (2008). A Life Beyond Work? Job Demands, Work-Life Balance, and Wellbeing in UK Academics. Journal of Human Behavior in the Social Environment, 17(1-2), 41-60. doi:10.1080/10911350802165478.

Messersmith, J. (2007). Managing work-life conflict among information technology workers. Human Resource Management, 46(3), 429451. doi:10.1002/hrm.20172.

Middleton, C. A. (2007). Illusions of Balance and Control in an Always-On Environment : A Case Study of BlackBerry Users. Ted Rogers School of Information Technology Management Publications and Research.

Ojala, S. (2011). Supplemental Work at Home among Finnish Wage Warners: Involuntary Overtime or Taking the Advantage of Flexibility? Nordic Journal of Working Life Studies, 1(2), 77-97.

O'Laughlin, E. M., \& Bischoff, L. G. (2005). Balancing Parenthood and Academia: Work/Family Stress as Influenced by Gender and 
Tenure Status. Journal of Family Issues, 26(1), 79-106. doi:10.1177/0192513X04265942.

Pallant, J. (2009). SPSS Survival Manual: A step by step guide to data analysis using SPSS (4th ed.). China: Allen \& Unwin.

Parasuraman, S., \& Simmers, C. A. (2001). Type of employment, work-family conflict and well-being: a comparative study. Journal of Organizational Behavior, 22, 551-568. doi:10.1002/job.102.

Rafnsdóttir, G. L., \& Heijstra, T. M. (2011). Balancing Work-family Life in Academia: The Power of Time. Gender, Work and Organization, 1-14. doi:10.1111/j.1468-0432.2011.00571.x.

Russell, H., Connell, P. J. O., \& McGinnity, F. (2009). The Impact of Flexible Working Arrangements on Work-life Conflict and Work Pressure in Ireland. Gender, Work and Organization, 16(1), 73-97.

Richardson, K., \& Benbunan-Fich, R. (2011). Examining the antecedents of work connectivity behavior during non-work time. Information and Organization, 21(3), 142-160. doi:10.1016/j.infoandorg.2011.06.002.

Santos, G. G., \& Cabral-Cardoso, C. (2005). Work-family culture in academia: a gendered view of work-family conflict and coping strategies. Gender in Management: An International journal, 23(6), 442-457. doi:10.1108/17542410810897553.

Skinner, N., \& Pocock, B. (2008). Work-life conflict: Is work time or work overload more important? Asia Pacific Journal of Human Resources, 46(3), 303-315. doi:10.1177/1038411108095761.

Sturges, J., \& Guest, D. (2004). Working to live or living to work? Work/life balance early in the career. Human Resource Management Journal, 14(4), 5-20.

Tight, M. (2010). The Golden Age of Academe: Myth or Memory? British Journal of Educational Studies, 58(1), $105-116$. doi:10.1080/00071000903516502.

Valcour, M. (2007). Work-Based Resources as Moderators of the Relationship Between Work Hours and Satisfaction With Work Family Balance. Journal of Applied Psychology, 92(6), 1512-1523. doi:10.1037/0021-9010.92.6.1512.

Venkatesh, A, \& Vitalari, N. P. (1992). An Emerging Distributed Work Arrangement: An Investigation of Computer-Based Supplemental Work at Home. Management Science, 38(12), 1687-1706.

Westenholz, A. (2006). Identity, Times and Work. Time \& Society, 15(1), 33-55. doi:10.1177/0961463X06061349.

Ylijoki, O. H. (2010). Future orientations in episodic labour: Short-term academics as a case in point. Time Society, 19(3), 365-386. doi:10.1177/0961463X10356220 
